\title{
La Nueva Novela Vista Desde Cuba
}

El tema es vasto y se presenta bajo múltiples formas. Para no perderse en el laberinto de textos ínfimos o accidentales, es preferible ceñirse al hilo de una distinción básica. Desde el triunfo de la revolución cubana, es posible señalar dos niveles de la política cultural del régimen: (a) el nivel político, que está determinado por los funcionarios culturales pero que en definitiva es dependiente de las más altas autoridades; (b) el nivel crítico que intenta esbozar una poética revolucionaria pero no consigue siempre independizarse de la presión política y burocrática. El primer nivel determina la estrategia de una política cultural que ha conocido ya notables cambios. El Caso Padilla es, tal vez, el más notorio, aunque no el único. El segundo nivel determina una serie de actividades críticas (centradas sobre todo en Casa de las Américas) que merecen ser examinadas con algún detalle. En una cultura de dirección totalmente centralizada como la cubana es imposible distinguir siempre entre estos dos niveles: se solapan, se mezclan, se confunden. Aún asi, vale la pena intentar el análisis.

Forzosamente, esta exposición sobre la nueva novela latinoamericana en Cuba habrá de ser panorámica. No podrá registrar todo lo que se ha escrito, ni tendrá en cuenta todos los autores estudiados. Por razones de síntesis, he preferido seguir la fortuna cubana de algunos autores básicos-Carpentier y Lezama, Cabrera Infante y Severo Sarduy, Onetti y Rulfo, Cortázar, Garcia Márquez y Fuentes-a pretender abarcarlo todo. También me he ceñido cronológicamente. La fecha inicial es, naturalmente, 1959, cuando empieza una política cultural revolucionaria en Cuba. La final es 1971, cuando el Caso Padilla provoca escisiones en el campo internacional, y destruye buena parte de la obra realizada hasta entonces. Entre esas fechas se sitúa este trabajo. ${ }^{1}$

II.

La política cultural del Gobierno revolucionario cubano ha tenido una importancia decisiva en la creación y promoción de la nueva novela latinoamericana. Esa importancia

${ }^{1}$ Para un enfoque de la crítica posterior a 1971 véase en este mismo número el trabajo de John Deredita, "Vanguardia, ideología y mito", y la reseña de Roberto González Echevarría del lib̆to de Manuel Cofiño López. 
no depende ya de la relativa pequeñez de la isla y sus comparativamente reducidos medios de publicidad. Tampoco depende de las restricciones de una política cultural que es al mismo tiempo ideológica, ni de las restricciones impuestas fuera de la isla por el bloqueo norteamericano y los satélites de la OEA. Todos estos factores--que serían francamente negativos y habrian impedido la influencia de Cuba en la orientación y valoración de la nueva novela latinoamericana-- han sido compensados por un elemento que hay que tener en cuenta y sin el cual el proceso que vamos a examinar brevemente ahora no tendría explicación. Sí, es cierto que Cuba es pequeña, que no dispone de grandes medios editoriales, que está sometida a una dirección ideológica cada vez más monolítica y que el bloqueo impide la libre circulación de sus publicaciones. Todo esto es verdad. Pero también es verdad que desde el triunfo de la revolución cubana a fines de 1958, la abrumadora mayoría de la intelligentsia latinoamericana se puso al servicio de la revolución. Este fenónemo, que no tiene paralelo en la historia de la cultura de este continente, ha permitido a la cultura cubana proyectarse sobre toda América Latina a pesar del bloqueo, a pesar de la creciente rigidez de la fiscalización ideológica dentro de la isla, a pesar de la relativa pequeñez de las ediciones cubanas. Por un proceso de amplificación que podría calificarse de reacción en cadena, lo que se publica o decreta desde Cuba cobra inmediatamente efecto en cada uno de los países latinoamericanos (incluso en aquellos sometidos a regimenes militares antagonistas del cubano), y genera infinitas repercusiones. Un libro cubano, un artículo cubano, un manifiesto cubano, son reproducidos localmente, comentados, amplificados. De este modo, se burla el bloqueo, se vence el problema de las escasas ediciones cubanas, y se multiplica el impacto de lo que Cuba produce en el campo de la cultura. También se produce otro efecto importante: la cultura latinoamericana pierde una condición que tantos lamentaran en una época, la dispersión, la incomunicación, lo que Luis Alberto Sánchez llàmó en los años treinta la intersordera continental, ${ }^{2}$ para ofrecer en cambio el fenómeno de una cultura ideológicamente centralizada, una cultura que tiene una sede: La Habana, y una ideología, la de Cuba revolucionaria.

Para encontrar una situación semejante habría que remitirse a los años veinte y treinta en que el triunfo de la revolución soviética provocó una adhesión similar en la intelligentsia de Europa occidental y la América Latina, y (hasta cierto punto) en la de los Estados Unidos. Pero ahora el proceso está mucho más acentuado y se beneficia no sólo de importantes factores culturales (la lengua común, una cultura que tiene raíces similares) sino de una situación política internacional que permite a Cuba levantar con toda eficacia la bandera anti-imperialista. La polarización entre los Estados Unidos y la Unión Soviética, y la ubicación de Cuba en el campo del socialismo facilita esta misión anti-imperialista y convierte a Cuba, desde el punto de vista de la intelligentsia latinoamericana, en el único territorio de América libre del imperialismo norteamericano.

Todo esto es sabido, y si lo enfatizo ahora es porque me parece necesario recordarlo antes de empezar un recuento panorámico de la importancia decisiva que ha tenido la política cultural del Gobierno cubano en la promoción y difusión de la nueva novela latinoamericana. Sólo se puede entender esta importancia si se recuerda que lo que dice (o no dice) la crítica cubana sobre un determinado autor, un determinado libro o una

\footnotetext{
${ }^{2}$ Véase, Luis Alberto Sánchez, Vida y pasión de la cultura en America (Santiago de Chile: Ercilla, 1935), p.18.
} 
determinada publicación, habrá de reproducirse fielmente a lo largo y a lo ancho del continente latinoamericano. De manera que cuando examinemos esas opiniones, u omisiones, estaremos examinandoopiniones u omisiones que tienen un área de difusión mucho mayor que la relativamente confinada donde fueron emitidas. De hecho, no es una exageración decir que a un nivel de opinión general, la opinión o la omisión cubana pesa más que la de cualquier otro centro cultural.

III.

A veces se olvida (no siempre involuntariamente) que el triunfo de la Revolución Cubana es uno de los factores determinantes del Boom. Lo es por la mera fuerza de las circunstancias políticas, que proyectan de golpe, hacia el centro del ruedo político internacional a la pequeña nación de nueve millones de habitantes, y con ella, a un continente olvidado de doscientos millones. De golpe, Cuba y América Latina son noticia. Además, el Gobierno de Fidel Castro asume una posición cultural decisiva y que tendrá incalculables beneficios para toda América Latina. Sin descuidar a escala nacional el problema de la educación y sobre todo del analfabetismo, la Revolución Cubana proyecta en sus primeros años una política cultural a escala latinoamericana. Para romper el bloqueo, Cuba crea en 1960 una institución, Casa de las Américas, que por algunos años se convertirá en el centro revolucionario de la cultura latinoamericana.

Esa institución, que dirige una de las heroinas de la revolución, Haydée Santamaría, realiza muchas cosas. Entre las más importantes está la fundación de una revista bimestral, Casa de las Américas, cuyo primer número es de junio-julio 1960. Los directores entonces son Fausto Masó y Antón Arrufat. A partir de marzo-abril 1961, queda Arrufat como único director. Sólo en 1965 habrá otro cambio de dirección. Para esa fecha, Casa de las Américas se ha definido como abierta a las formas más experimentales de la nueva literatura, coincidiendo así con el primer movimiento de la cultura revolucionaria. El refinado Alejo Carpentier es entonces director de la editorial del Estado; Robbe-Grillet y otros pontífices del Nouveau Roman alternan con Marx y Engels en los quioscos de libros. La intelectualidad europea, y sobre todo la francesa, subraya y aplaude maravillada el eclecticismo de esta orientación de lá cultura revolucionaria.

Con el número 30 (mayo-junio, 1965) pasa a dirigir Casa de las Américas el poeta Roberto Fernández Retamar que ya antes de la revolución se había destacado por su labor en los círculos estudiantiles (era católico, entonces) y por su obra de crítico y profesor. Fue profesor visitante de la Universidad de Yale, y antes de la caída de Batista habia publicado en una prensa universitaria del estado su Idea de la estilistica. ${ }^{3}$ Pero la revolución triunfante metamorfoseó a Fernández Retamar en ideólogo literario del socialismo cubano. Bajo su dirección, Casa de las Américas expande el comité de colaboración, en que figuraban ya escritores como Julio Cortázar (desde el no. 13-14, julio-octubre 1962), para

3 Véase, Roberto Fernández Retamar: Idea de la estilistica (Universidad Central de las Villas, Departamento de Relaciones Culturales, 1958). El libro se publica en visperas del triunfo de Fidel. Hay una alusión pedagógica en las "Advertencias" que sirven de prólogo: "Las circunstancias anormales en que se halla el país, de tan dolorosa consecuencia en nuestros centros mayores de estudio, al hacer imposible la prosecución de las clases han obligado a posponer el curso." En efecto la revolución, entre otras cosas, obligó a suspender las clases. 
incorporar también a Mario Vargas Llosa (no. 32, setiembre-octubre 1965). Como Cortázar y Vargas Llosa residían entonces en Paris, el contingente parisino de la revista resultaba fortalecido. Con la dirección de Fernández Retamar empieza, aunque tal vez no por su iniciativa, un endurecimiento de la línea ideológica de la revista: endurecimiento que llevará a la ruptura con muchos de sus colaboradores más distinguidos cuando estalle el Caso Padilla. A partir del número 67 (julio-agosto 1971) el Comité de Colaboración es abruptamente eliminado de la revista. El discurso de Fidel al cerrar el Congreso de Educación y Cultura (abril 23, 1971) demuestra que ésta no era una política de la revista sino de la revolución. Allí Fidel se manifestó explícitamente contra "los seudoizquierdistas descarados que quieren ganar laureles viviendo en Paris, en Londres, en Roma." Estas palabras confirmaron una ruptura que era fácil profetizar desde la reacción de estos mismos intelectuales que denunciaron la invasión de Checoeslovaquia por el Ejército soviético (agosto 2,1968 ) y la decisión de defender esa intervención militar y política por parte de Fidel.

Pero volvamos un poco atrás. Casa de las Américas también ha organizadc Congresos, festivales y concursos. El más famoso es el Premio anual que se otorga a partir de 1960 en varias categorías (ensayo, novela, cuento, teatro, poesía) y que recientemente ha sido ampliado para incluír también testimonio. En los jurados que otorgan dichos premios participan nombres destacados de la cultura latinoamericana, y extranjera de hoy. Casa de las Américas también publica libros: reediciones de clásicos de la literatura latinoamericana, algunos olvidados o conocidos sólo en sus respectivos paises; reediciones de obras nuevas y aún novísimas que se ponen al alcance del lector hispanoamericano; recopilaciones, ideológicamente orientadas, de estudios críticos sobre autores recientes.

El impacto de esta política cultural--especialmente en la década del sesenta--no deja de sentirse en todo el continente, y aún fuera de él. El semanario uruguayo, Marcha, recibe un impulso extraordinario del ejemplo cubano y se convierte en uno de los órganos de difusión y amplificación de una política cultural revolucionaria que está reducida en su influjo por el bloqueo. En México y en Argentina (para citar dos ejemplos más) tanto Siempre como el nuevo semanario Primera Plana, siguen en esos años muy de cerca el ejemplo de Casa y aportan a él su esfuerzo. Este último semanario organiza incluso un Concurso de novela, patrocinado también por la Editorial Sudamericana, de Buenos Aires, que resulta más notable por sus jurados (José Bianco, Mario Vạrgas Llosa, Juan Carlos Onetti, Severo Sarduy, Leopoldo Marechal, Gabriel García Márquez) que por las obras premiadas.

Pequeñas agresivas editoriales (muchas de ellas ya desaparecidas, como las que patrocinaron el semanario Primera Plana y el semanario Marcha) van a recibir en los años sesenta un fuerte apoyo cubano. Me refiero a casas como Era, de México, Jorge Alvarez y Galerna de Buenos Aires, la Editorial Universitaria, de Santiago de Chile, o Arca, de Montevideo. Muchas revistas se crean para sostener en cada país la línea de la liberación cultural latinoamericana que Cuba patrocina tan activamente. Hay un permanente intercambio, viajes y Congresos, manifiestos y coediciones y números de homenaje, que permiten burlar el bloqueo y desarrollan una verdadera revolución cultural en toda América Latina. Aunque el Brasil queda un poco aislado por su lengua de gran parte de este movimiento, en el teatro y en el cine brasileño se establecen las bases de un in- 
tercambio permanente con Cuba.

En síntesis, se puede decir que el Gobierno cubano logró burlar el bloqueo y logró crear no sólo institutos y órganos que, desde la isla, difundieron su política cultural sino que también logró burlarlo por medio de institutos y órganos publicitarios latinoamericanos que funcionaron fuera de Cuba. Esta iniciativa de la Revolución constituye el contexto más urgente y dinámico para la expansión que habría de ser calificada, desde otro ángulo, del Boom de la novela latinoamericana. No es el cubano un boom capitalista, promovido por industriales y publicistas; es un boom ideológico, promovido por un pequeño pais sitiado pero que tiene el apoyo internacional del vasto mundo socialista y que en toda la América Latina se basa en la izquierda culturalmente poderosísima del continente. Sin este boom (que no es sólo el de la novela sino que abarca también, y sobre todo, el ensayo y la poesía), el otro Boom, con mayúscula, que es el que todos comentan, tal vez no hubiera llegado a ocurrir, o no habría tenido la misma repercusión. Pero ésta es otra historia, y ya la he contado en otra ocasión. ${ }^{4}$

IV.

En los quince años largos que lleva de existencia la política cultural cubana, y a pesar de notables cambios de dirección dentro de la misma línea socialista (cambios que aquí no podemos historiar), ¿qué impacto ha tenido Cuba en la valoración de la nueva novela? El tema es vasto, la documentación inmensa y el tiempo de que dispongo es limitado. Por lo tanto, me parece más eficaz examinar con algún detalle sólo ciertos aspectos decisivos de esa valoración. Me concentraré, pues, en tres series de escritores a los que la Revolución cubana ha tratado en forma diferente pero de tal suerte que permite descubrir ciertas grandes líneas y, tal vez, el esbozo no ya sólo de una estrategia cultural sino de una poética revolucionaria. Esos grupos son, lo admito, arbitrarios y su partición obedece tal vez sólo a motivaciones pedagógicas. Pero son los únicos que permiten una exposición panorámica como ésta. Empezaré por el grupo de los novelistas cubanos que se han destacado a partir de la Revolución.

Excluyo de ese grupo a Alejo Carpentier no sólo porque su obra narrativa era ya famosa antes de la Revolución y no necesitaba de ésta para su difusión, sino porque por motivos que son dificiles de determinar objetivamente, su obra literaria no ha obtenido en Cuba la atención crítica que merece y que ha obtenido en otros lugares. Dedicaré sólo un minuto a la paradójica situación de Alejo Carpentier dentro de la cultura cubana. Desde un punto de vista oficial, no puede negarse que la Revolución cubana ha reconocido la importancia y eminencia de su obra. No sólo fue designado Director de la Editorial del Estado en la primera etapa de la revolución cultural sino que después de dejar esta posición importantísima, fue designado Consejero Cultural del Consulado Cubano en París: la posición cultural más destacada de la Revolución en Europa. Tampoco cabe dudar de la adhesión oficial de Alejo Carpentier a la Revolución y al régimen cubano. Su firma aparece en cuanto manifiesto literario se emite desde La Habana, su colaboración en publicaciones de la isla es sobresaliente y (lo que es más importante) su labor de difusión de la política

4 Véase mi libro, El Boom de la novela latinoamericana (Caracas, Tiempo Nuevo, 1972). 
cultural cubana en Francia y en Europa es de primer orden.

Sin embargo, y a pesar de todo, la obra narrativa de Alejo Carpentier no ha sido estudiada en Cuba con la atención que se ha dedicado a otros novelistas cubanos y sobre todo extranjeros que son incluso más jóvenes que Carpentier. Hablo, es claro, de lo que ha ocurrido hasta el año 1971, fecha que me he impuesto como límite de este trabajo según ya he indicado. Pero me parece suficientemente significativo que en por lo menos doce años de política cultural cubana, Alejo Carpentier no haya sido destacado por la crítica cubana con trabajos de la calidad de los que se han publicado sobre él en América Latina, en Europa y en Estados Unidos, en el mismo periodo de tiempo. Su caso resulta, pues, paradójico. ${ }^{5}$

De otra índole es la situación de Lezama Lima ante la crítica cubana. Antes de la Revolución, su obra era conocida escasisimamente fuera de la isla y aún dentro de la isla era estimada sólo por un grupo de poetas que él había reunido en torno de sí en revistas minoritarias aunque decisivas, como Origenes. Con la Revolución todo esto cambia radicalmente. Lezama Lima emerge de la relativa oscuridad, los escritores más jóvenes se declaran sus discípulos, y aún aquellos más irreverentes (como Heberto Padilla en su primera época, o Guillermo Cabrera Infante) lo reconocen sin embargo. Un escritor secreto, un poeta hermético, un ensayista órfico, Lezama Lima se convierte de pronto en el centro de una literatura de vanguardia que representa lo más avanzado de la cultura revolucionaria. Entonces estalla la bomba de Paradiso.

Como se sabe, Lezama Lima trabajaba en esta novela desde por lo menos los años cuarenta. Ya en 1949, la revista Origenes publicó los cuatro primeros capitulos, de deleitosa y proustiana evocación familiar. Pero en ese entonces muy pocos leyeron su texto. Por razones de índole familiar, que son también similares a las que Proust tuvo para demorar hasta la muerte de su madre la redacción final de $A$ la recherche du temps perdu, Lezama no se decide a publicar su novela hasta la muerte de Rosa Lima. Pero el libro que envía para su publicación en las ediciones UNEAC, patrocinadas por la muy oficial Unión de Escritores y Artistas Cubanos, es un libro maldito. En momentos en que el Gobierno cubano había decidido la persecución de los homosexuales, su concentración en campos de trabajo y reeducación de la UMAP, Lezama Lima entrega una novela que presenta en forma directa y a la vez metafórica las actividades homosexuales de algunos de sus protagonistas; una novela en que con un brillo casi único en las letras hispánicas, se describe barrocamente acoplamientos y sodomías, se desarrolla una compleja teoría de la homosexualidad, basada en textos clásicos (San Agustín, Dante)o en teorías más recientes. El libro causa un escándalo y divide la opinión dentro de la UNEAC. Se decide no

\footnotetext{
5 Con posterioridad a la redacción de este trabajo en el otono de 1974, Casa de las Américas ha publicado un número que contiene cinco artículos sobre Carpentier. Sólo uno de ellos, está escrito por un investigador cubano, Adolfo Cruz-Luis. Véase, Casa de las Américas, No. 87 (noviembre-diciembre 1974), pp. 48-59. El trabajo se titula, "Latinoamérica en Carpentier: genésis de lo real maravilloso." No hay ninguna referencia en su articulo a la ruptura de Carpentier con el grupo surrealista que capitaneaba Breton ni a la omisión de toda referencia directa al maestro francés en el prólogo a El reino de este mundo. Este tema ha sido analizado in extenso por mí en "Lo real y lo maravilloso en El reino de este mundo,"' trabajo de 1971, ahora recogido en Narradores de esta América (II), (Buenos Aires: Editorial Alfa Argentina, 1974), pp. 64-98. En un trabajo de 1973, Roberto González Echevarria ha ampliado aún más el análisis crítico. Véase, "Isla a su vuelo fugitiva. Carpentier y el realismo mágico," en Revista Iberoamericana, vol. XL, no. 86 (Universidad de Pittsburgh, Instituto Internacional de Literatura Iberoamericana, enero-marzo 1974), pp. 9-63.
} 
publicarlo pero se teme la reacción cuando se sepa que un libro de un autor tan importante como Lezama Lima ha sido censurado. Incapaces de afrontar una decisión definitiva, la UNEAC decide consultar a la autoridad suprema. Fidel Castro lee el libro y le gusta, a pesar de que reconoce su inoportunidad política. En definitiva, Fidel resuelve que el libro debe publicarse porque puede ser más contraproducente censurarlo. El libro saldrá, pues, en 1966, editado por la UNEAC, aunque en una edición de sólo cuatro mil ejemplares que se agota casi inmediatamente. Digo sólo cuatro mil ejemplares porque las ediciones de UNEAC son normalmente de cinco mil a diez mil ejemplares. Con una reducción de la tirada se esperaba, sin duda, reducir el impacto de la novela.

Por la misma razón, se produjo una tal vez espontánea y limitada conspiración de silencio en torno de ciertos aspectos de la obra. No se silenció su aparición e incluso se publicaron cinco reseñas, aunque la Revista de Casa de las Américas significativamente no publicó ninguna. Pero de esas reseñas sólo una, publicada por César López en la revista Unión, de la UNEAC (abril-junio 1966), examinaba con cierta extensión los aspectos homosexuales del libro. ${ }^{6}$ Aunque los subordina a otros, aunque no descubre el entronque ideológico y poético de este tema con los centrales del libro, por lo menos ya en 1966 y en plena represión, César López se atreve a decir algo. En la misma revista se publica a fines de año un artículo especialmente escrito por Julio Cortázar desde Paris para ayudar a ventilar el tema y romper el relativo silencio. Con gran estilo ensayistico e invocando inesperados antecedentes--por ejemplo, apunta Cortázar las implicaciones homosexuales del Viaje al centro de la tierra, de Jules Verne--, su artículo aborda ese aspecto de la novela y a partir de él, desarrolla una compleja aunque arbitraria lectura del libro. Es una de las aproximaciones más personales y provocativas que esta personal y provocativa novela ha suscitado. ${ }^{7}$

Incluso fuera de Cuba, muchos partidarios de la revolución prefirieron ignorar estos aspectos peligrosos del libro. En un brillante artículo escrito para la revista peruana $A$ maru (enero 1967), Mario Vargas Llosa omite toda mención al tema, tan importante para el desarrollo narrativo de Paradiso como para su formulación de una ideología cultural y de una teoría de la escritura poética. ${ }^{8}$ El silencio de Vargas Llosa parece responder a un cuidado de no acentuar este aspecto del libro en momentos en que en Cuba continuaba la persecución de los homosexuales. De todas maneras, este problema social está más atenuado, aunque no ya resuelto en Cuba, cuando se publica en La Habana, en la serie Valoración Múltiple de Casa de las Américas, un volumen de 575 páginas, compilado por Pedro Simón y titulado, Recopilación de textos sobre José Lezama Lima. Es el cuarto volumen de una serie que ha honrado ya a tres narradores latinoamericanos, como se verá más adelante. Se recogen en este volumen no menos de diecisiete trabajos críticos sobre Lezama. Participan en esta sección siete críticos cubanos pero de ellos sólo dos (César

\footnotetext{
6 Está recogido en Recopilación de textos sobre José Lezama Lima, texto de la serie Valoración múltiple de Casa de las Américas, que preparó Pedro Simón (La Habana, 1970), pp. 182-190.

7 También es tá recogido en Recopilación (v. nota 6), pp. 146-168.

${ }^{8}$ Véase, "Paradiso, de José Lezama Lima," en Amaru, no. 1 (Lima, enero 1967), pp. 72-75. Véase también un intercambio de cartas entre Vargas Llosa y Emir Rodríguez Monegal, "Sobre el Paradiso de Lezama," en Mundo Nuevo, no. 16 (Paris, octubre 1967), pp. 89-95. Estas cartas están recogidas en mis Narradores (II), pp. $141-155$
} 
López, Reynaldo González) se ocupan de Paradiso. Ya me he referido al primero.

El artículo de Reynaldo González es mucho más largo e importante. ${ }^{9}$ Ha sido escrito obviamente para esta Recopilación, ya que no se indica en la detallada bibliografía del volumen ninguna fuente. El entronque del tema homosexual con las preocupaciones básicas del libro se hace con una perspectiva crítica más amplia y satisfactoria que la del trabajo de César López. La parcial conspiración de silencio no ha funcionado aquí, obviamente. La razón es clara. Estos volúmenes de la serie Valoración Múltiple tienen una difusión considerable (cinco mil ejemplares, en este caso) pero limitada por su misma naturaleza crítica. Aunque habrán de ser consultados por especialistas, dentro y fuera de Cuba, su "peligrosidad cultural" (desde el punto de vista de la actitud oficial del régimen con respecto a los homosexuales) resulta disminuída. De esta manera, là relativa conspiración de silencio deja de funcionar a ciertos niveles especializados, aunque continúa funcionando eficazmente a nivel de la más amplia difusión cultural. En tanto que Casa de las Américas no comenta Paradiso, Valoración Múltiple dedica un volumen entero a Lezama Lima y examina los aspectos homosexuales del libro.

El contraste entre la actitud de la crítica cubana en el caso de Lezama Lima y en el de Carpentier requeriría más estudio. Es obvio que aquí se manifiesta una curiosa paradoja. Por un lado, está Carpentier, escritor oficial y funcionario destacado del régimen, famoso dentro y fuera de Cuba. Por el otro, está Lezama Lima, que sólo alcanza difusión a partir de la Revolución, y que a pesar de su adhesión explícita al régimen no ha disimulado ni su catolicismo ni su homosexualidad. Una situación como ésta, en la Unión Soviética, por ejemplo, sería resuelta en forma coherente. El silencio y la discreta postergación para Lezama Lima; la promoción infatigable de Carpentier. En Cuba las cosas no son tan simples. Es cierto que a nivel de la difusión de la obra, Carpentier continúa a la cabeza, pero desde el punto de la valoración crítica, Lezama Lima es, sin duda, el novelista que la crítica cubana ha estudiado con más dedicación y respeto. Como además, su obra novelística se inscribe en la órbita de una prodigiosa actividad como poeta y crítico de poesía, se puede afirmar sin lugar a dudas que Lezama Lima es hoy el escritor más im. portante de Cuba no sólo para los jóvenes poetas y narradores, sino también para la crítica. Esa valoración ha influído decisivamente en la consideración de su obra entera fuera de Cuba. Hoy, en América Latina, y en el mundo occidental, la obra de Lezama Lima ha sido reconocida como una de las decisivas de este siglo, y su nombre ha terminado por ser situado por su calidad e importancia junto al de Borges y el de Octavio Paz.

\section{V.}

Muy distinta es la situación en lo que se refiere a los novelistas cubanos de promociones más recientes-que constituyen el segundo grupo de esta presentación. La política cultural cubana ha desconocido o atacado a dos de los que fuera de Cuba son considerados entre los más grandes narradores de hoy--me refiero a Guillermo Cabrera Infante y Severo Sarduy - ; también ha silenciado o postergado el reconocimiento de un joven narrador que, a pesar de vivir en Cuba y recibir premios alli encuentra enormes

9 Está recogido en Recopilación (v. nota 6), pp. 219-249. 
dificultades en publicar su obra. Me refiero a Reinaldo Arenas, cuyo segunda novela, la brillantísima evocación de la vida y personalidad de Fray Servando Teresa de Mier y que se titula El mundo alucinante, ha sido censurada en Cuba. La única edición en español que conozco es la publicada por Diógenes, en México. El libro ha tenido, sin embargo, éxito de crítica y de público en sus traducciones al francés e inglés. ${ }^{10}$

En el caso de Cabrera Infante y Severo Sarduy es comprensible que la crítica oficial cubana no esté muy dispuesta a estudiar sus respectivas obras. Cabrera Infante abandonó definitivamente Cuba en 1965 y desde entonces sus relaciones con el establecimiento han ido deteriorándose hasta el punto que su nombre jamás es mencionado sin el apelativo, " agente de la CIA", que equivale al conocido expletivo, "hijo de puta", que se usa en medios menos políticos y con la misma base documental. Son muy conocidas las polémicas en que se ha visto envuelto Cabrera Infante desde la discusión, iniciada por Heberto Padilla en El caimán barbudo, a fines de 1967, al elogiar públicamente en Cuba Tres tristes tigres y atacar Pasion de Urbino, de Lisandro Otero, que era entonces Vicepresidente del Consejo Nacional de Cultura. En la subsiguiente polémica habrá de participar un tal "Leopoldo Avila", que se destaca sobre todo por la agresividad ordinaria de sus ataques. Cito algunas de sus más interesantes objeciones:

[Tres Tristes Tigres sería para "Leopoldo Avila'] “'algo que se llama novela por no pasar trabajo para encontrarle un nombre apropiado (...) es una larga colección de cuentos, pedazos de narraciones, etc., una especie de rompecabezas con el que Caín quiere asombrar al mundo (...) Objetivamente : toda valoración de esta obra está falsificada por el amiguismo y la política. Nadie que la lea puede colocar a Caín junto a García Márquez, Vargas Llosa, Cortázar, Fuentes o Carpentier ni aún Asturias. (...) Es la Habana de los borrachos homosexuales, los toxicómanos y las prostitutas: La Habana de Caín, en una palabra. (...) Llorar como magdalenas sobre sus recuerdos es arbitrario y poco masculino. Fue este Mr. Kein el primero en abrir el cauce del individualismo y la extravagancia en el arte. ${ }^{11}$

En otros pasajes, "Leopoldo Avila"' habla del "lenguaraz escritor"'; dice que la Revolución no puede levantar "estatuas a los gusanos" y educar a una generación "'adorando traidores". Finalmente lo llama, "triste gatito del imperialismo". En el mismo trabajo "Leopoldo Avila" ataca violentamente a Padilla y habla de desenmascar a los escritores contrarrevolucionarios.

Abriré aquí un paréntesis sobre la inconsistencia polémica de "Leopoldo Avila". Aunque acusa a Heberto Padilla y a otros de enmascararse, parece olvidar que él mismo está escribiendo bajo seudónimo y que si odia tanto las máscaras, debió mostrar su verdadera cara. Según opina Lourdes Casal en una excelente recopilación de textos sobre el Caso Padilla, "Leopoldo Avila"' es seudónimo del conocido crítico estalinista, José

10 Véase, Reinaldo Arenas: El mundo alucinante. (Una novela de aventuras), (México: Diógenes, 1969 ), 272 $\mathrm{pp}_{11}$

11 Los textos de "Leopoldo Avila" han sido recogidos en dos artículos, publicados en la revista Verde Olivo (La Habana): “Las respuestas de Cain,"' (año IX, no. 44, noviembre 3, 1968) y "Sobre algunas corrientes de la crítica literaria en Cuba,' (año IX, no. 47, noviembre 24, 1968). Todas las citas de este trabajo pertenecen a dichos articulos. 
Antonio Portuondo. ${ }^{12}$ Sea quien fuere, él expresa desde el órgano oficial del póderoso Ejército Cubano la opinión oficial sobre Cabrera Infante. Que esto nada tenga que ver con la crítica literaria no impide que en otras publicaciones latinoamericanas se siga la misma línea. Así, por ejemplo, Marcha publicól en: 1968 un trabajo de Mario Benedetti sobre la cultura cubana actual en que lo único que se decía sobre Cabrera Infante era que estaba patrocinado por lios USA. No había en el artículo ni una palabra sobre su obra literaria. ${ }^{13}$

El caso de Severo Sarduy es menos espectacular pero el silencio en torno de su obra no menos sólido. Nunca ha sido atacado en la forma terrible en que lo ha sido Cabrera Infante pero desde su partida para Francia en 1962, su obra ha sido generalmente ignorada en Cuba. El hecho de que Sarduy pertenezca en Paris a un grupo de escritores de izquierda que se reúnen en las Editions du Seuil no ha afectado para nada la cotización oficial de su nombre en la isla. Ha sido y sigue siendo ignorado por la crítica cubana, y por aquellos. críticos latinoamericanos que sólo leen los libros autorizados en La Habana.

Entre tanto, la cultura cubana ha tratado de patrocinar otros novelistas. Los más famosos son Edmundo Desnoes y Lisandro Otero. Ambos pertenecen a la misma generación de Cabrera Infante. Ambos tienen importantes puestos oficiales. Las ediciones de sus libros reciben atención crítica y en 1967 hasta se organizó una encuesta, en el periódico juvenil, El caimán barbudo, sobre Pasión de Urbino. La única novela de Desnoes que ha atraído la atención del público internacional es Memorias del subdesarrollo, 1965. Pero ni la novela de Lisandro Otero ni ésta de Desnoes han logrado ingresar a la lista de grandes novelas latinoamericanas. Toda la propaganda oficial no ha podido darles el lugar que Tres tristes tigres, De donde son los cantantes, Cobra y El mundo alucinante han conseguido por sus valores literarios. Desde este punto de vista, el fracaso de la crítica cubana, tanto desde el punto de vista de sus ataques, o sus omisiones y silencios, como del punto de vista de su promoción sostenida de ciertas obras ha tenido un efecto similar al logrado por la crítica soviética en sus esfuerzos por promover a Konstanin Simonov (quién se acuerda de él hoy) o a Mijail Sholojov (quién lo lee a pesar del Premio Nobel).

VI.

El tercer grupo que me interesaría considerar ahora es el de los grandes narradores hispanoamericanos que se han revelado en estos últimos veinte años. Es bien sabido que muchos de ellos--Cortázar, Fuentes, García Márquez, Vargas Llosa, son tal vez los más conocidos--, han manifestado reiteradamente su adhesión a la causa cubana, han firmado incontables manifiestos. a favor, o en contra, de instituciones escogidas por la política cultural cubana para el elogio o la censura, y han contribuído en gran parte a la difusión de la revolución cultural con su esfuerzo. También es sabido que a partir del caso Padilla se ha producido una clara escisión en ese grupo. En tanto que Fuentes y Vargas Llosa continúan

12 La más completa recopilación que conozco de documentos relacionados con estas polémicas es el libro de Lourdes Casal, El Caso Padilla: Literatura y Revolución en Cuba (Documentos) (New York: Nueva Atlántida, 1971). También es útil la recopilación de documentos del primer número de la revista Libre (Paris, setiembrenoviembre 1971), pp. 95-145.

13 Cf. Mario Benedetti, "Situación actual de la cultura cubana", in Marcha, (Montevideo), diciembre 27, 1968; reproducido en el libro de Benedetti, Cuaderno cubano (Montevideo, Arca, 1969), pp. 109-110. 
proclamando su adhesión al socialismo pero insisten en su derecho a criticar los errores de la política cultural cubana, tanto Cortázar como García Márquez han suspendido ese derecho para apoyar la causa cubana sin reservas. Estos cambios en la estrategia de la revolución cultural han afectado naturalmente los juicios cubanos sobre la obra de estos narradores. Así, por ejemplo, Fuentes fue violentamente atacado ya en 1966 por su participación en el Congreso Internacional del P.E.N. Club en New York. Ese ataque aparecía en la misma carta abierta en que se acusaba a Pablo Neruda de terribles delitos contra la solidaridad socialista. ${ }^{14}$ Aunque Fuentes cons uió volver al favor de los cubanos y hasta envió alguna colaboración a Casa de las Américas, las relaciones se enfriaron hasta alcanzar el hielo dos años más tarde, en ocasión de la carta de protesta de destacados intelectuales europeos, norteamericanos y latinoamericanos publicada cuando se produjo la invasión soviética a Checoeslovaquia. Desde ese momento, Fuentes perdió contacto con los cubanos.

El caso de Mario Vargas Llosa es aún más dramático. Una primera discrepancia privada, que sólo se conoció públicamente cuatro años más tarde, ocurrió ya en 1967, cuando el jurado del premio de novela Rómulo Gallegos distinguió su novela, La casa verde (1966). En esa época, la política cultural cubana y la venezolana eran opuestas; el Gobierno venezolano perseguía las mismas guerrillas que alentaba Cuba. Vargas Llosa era uno de los miembros del Comité de Colaboración de Casa de las Américas. Para aceptar el premio decidió consultar a los cubanos. La respuesta de ellos fue terminante: Acepta los 23.000 dólares pero debes donarlos públicamente a los guerrilleros peruanos. Vargas Llosa no siguió el consejo. En cambio, prefirió hacer una declaración pública de su fe en la causa socialista y destacó a Cuba como el único país americano en que se cumple la justicia social. ${ }^{15}$ Un año más tarde, cuando la invasión a Checoeslovaquia, Vargas Llosa estaba con Fuentes entre los firmantes del manifiesto anti-soviético en tanto que Fidel Castro defendía públicamente la invasión por razones de política internacional. En 1971, el Caso Padilla llevó otra vez a Mario Vargas Llosa y a Fuentes a manifestarse en contra de una posición adoptada por el oficialismo cubano. Esta vez, la respuesta de Cuba fue terrible. Una carta de Haydée Santamaría, directora de Casa de las Américas, reveló el pedido que se le había hecho en 1967 de donar el premio Rómulo Gallegos a los guerrilleros. En vez de hacerlo, decía Haydée, Mario se compró una casa. ${ }^{16}$

Mucho más compleja es la situación de Cortázar frente a la política cultural cubana, En ocasión del caso Padilla su conducta fue bastante ambigua. Se recordará que ya en 1968 hubo un encontronazo entre el establecimiento cubano y Padilla. En aquel entonces el motivo fue un volumen de poemas, Fuera del juego, que un jurado internacional premió en el Concurso de la UNEAC, a pesar de las presiones de los organizadores cubanos del certamen. El libro y el autor fueron denunciados como contra-revolucionarios en una serie de artículos publicados en Verde Olivo, órgano del Ejército Cubano por el funcionario que se enmascara detrás del seudónimo de "Leopoldo Avila", El libro fue luego publicado

\footnotetext{
14 Véase mi articulo, “El PEN Club contra la guerra fria," en Mundo Nuevo no. 5 (Paris, noviembre 1966), pp. $85-90$

15 Véase el discurso de aceptación del Premio Rómulo Gallegos, en Mundo Nuevo, no. 17 (Paris, noviembre 1967), pp. 93-95.

16 Véase el intercambio de cartas entre Haydée Santamaría y Mario Vargas Llosa en Libre, no. 1, pp. 122-124.
} 
completo pero se le incorporó un largo texto de condenación redactado por la Dirección de la UNEAC. En ocasión de la publicación en Francia de una traduçción del libro--traducción que ostentaba en una faja la indiscreta pregunta: "Peut-on tre poete l Cuba?"--, un pequeño escándalo publicitario se armó en Paris. Para tratar de poner las cosas en su sitio, Cortázar publicó en Le Nouvel Observateur un artículo, 'L'affaire Heberto Padilla; ni trâtre ni martyr"' (abril 7, 1969), en que trataba de decir dos cosas simultáneamente: (a) que el libro había sido publicado en Cuba lo que indicaba la amplitud de miras del régimen, y embotaba las acusaciones de estalinismo, etc., que ya se estaban haciendo; (b) que el libro no era contrarrevolucionario sino revolucionario porque la crítica de la revolución, dentro de la revolución, no es contrarrevolución. Al tratar de quedar bien con tirios y troyanos, Cortázar sufrió considerables ataques por parte de ambos. Tres años después el segundo y más grave escándalo que se conoce con el nombre de Caso Padilla habría de tener consecuencias aún más catastróficas para Cortázar. En un primer momento el narrador argentino firmó la primera carta de protesta por la prisión de Padilla dirigida a Fidel Castro. Luego se conoció la violenta reacción cubana: carta de Haydée Santamaría a Mario Vargas Llosa; eliminación del Comité de Colaboración de Casa de las Américas; discurso de Fidel Castro en que se felicita de no contar inás con la adhesión de esos intelectuales pseudoizquierdistas, y les dice:

"Cuando nos vayan a defender les vamos a decir: 'No nos defiendan, compadres, por favor, no nos defiendan!' ‘No nos conviene que nos defiendan!' ‘No nos conviene que nos defiendan!', les diremos."

Entonces, Cortázar cambió de rumbo una vez más. No firmó la segunda carta de los intelectuales y envió en cambio una adhesión a los cubanos, acompañada de un poema, "Policrítica en la hora de los chacales" 17 que no es tal vez lo mejor que ha escrito en su vida. (Así como los poetas insisten en escribir novelas, los narradores insisten en escribir poesía. Rara vez aciertan.) La adhesión y el poema reflejaban un estado emocional cercano al pánico. Para agravar más las cosas, el primer número de la revista Libre, entonces fundada en Paris por el grupo de escritores latinoamericanos residentes y que tenía financiación de la siniestra familia Patiño, acababa de salir. Esta revista había sido planeada como compañera de ruta de Casa de las Américas. Habría de completar desde Europa la tarea que aquélla realizaba desde América. En el primer número había una colaboración de Cortázar, que también figuraba en el Consejo de Dirección. Pero como el número se retrasó, el Caso Padilla estalló entre tanto, y en ese primer número la Dirección recogió los textos de la polémica internacional que el Caso había suscitado. En vez de aparecer como zaguera de su hermana mayor, Libre aparecía como una publicación crítica y hasta opuesta. Cortázar se vió aún más comprometido en sus intentos de reacercamiento.

Estos detalles de estrategia cultural explican la ambigüedad de sus relaciones con Cuba. También explican que tanto en su caso, como en el de Fuentes o el de Vargas Llosa, la crítica cubana no se haya destacado especialmente en analizarlo. Hubo una época idílica de promoción y elogio, pero ninguno de los tres considerables novelistas recibieron la atención

17 Está recogido en Libre, no. 1, pp. 126-130. 
que otros (no menos considerables pero más ortodoxos en sus actitudes políticas) han recibido. No es de extrañar pues, que en la serie Valoración Múltiple no hubiera hasta 1971 por lo menos ni un Cortázar, ni un Fuentes ni un Vargas L.losa. Hay otros novelistas, sin embargo.

\section{VII}

La selección cubana es interesante. Junto a volúmenes temáticos, la serie ha publicado, como ya se ha visto, una recopilación dedicada a Lezama Lima y otras tres, dedicadas a Juan Carlos Onetti, Juan Rulfo y Gabriel Garcia Márquez. El volumen sobre Onetti (197 pp.; tirada de cuatro mil ejemplares) es de 1969 y fue preparado por Reinaldo García Ramos. Recoge dieciséis trabajos mayores y una breve selección (seis items) de "Otras Opiniones". No hay un solo trabajo cubano aunque en la bibliografía se indica uno (de Calvert Casey, publicado en la Revista de Casa de las Américas en 1964) que tal vez hubiera merecido inclusión. ${ }^{18}$ La exclusión de ese trabajo obedece quizá al hecho de que Casey estaba entonces exilado voluntariamente en Europa. Siendo homosexual, prefirió cortar sus vínculos con un Gobierno que perseguia a los homosexuales. El mismo año que sale el volumen, Casey se suicidó. La ausencia de su trabajo me parece sintomática. Como me parece sintomática también la circunstancia de que se dedique un número especial de la serie a Onetti. Este gran escritor uruguayo lo merece, sin duda. Además, su posición política en estos años ha sido muy clara. Aunque hasta los años sesenta militó en uno de los dos partidos conservadores del Uruguay, Onetti siempre ha tenido vínculos con la izquierda y ha apoyado públicamente la Revolución cubana. Dedicarle un volumen, a pesar del aparente desinterés que ha manifestado la crítica cubana por su obra, era una manera de atraer la atención sobre esta figura decisiva en la creación de la nueva novela latinoamericana. Aún así, es revelador que el volumen no recoja ningún trabajo cubano sobre Onetti. Tal vez no existe.

El volumen dedicado a Juan Rulfo (169 pp; tirada de cuatro mil ejemplares) está organizado por A.B.R., iniciales de Antonio Benito Rojo, y fue publicado en 1969. Recoge quince estudios largos, tres de los cuales han sido escritos por críticos cubanos: Reinaldo Arenas, Belkis Cuza Malé (que es la mujer de Heberto Padilla) y el compilador. El trabajo de Belkis Cuza Malé es una mera reseña; el de Rojo abunda en una prosa poética que requiere la fulminante lucidez de Octavio Paz para poder funcionar. El trabajo de Arenas es el único que aporta algo al tema. Este joven novelista cubano es uno de los mejores críticos de narrativa. Muy leído, es capaz de descodificar los textos con una imaginación y una experiencia literaria que falta por lo general a sus colegas. Aunque la colaboración cubana sea escasa, este volumen cumple una función importante al recoger parte de lo que la crítica internacional ha dicho sobre el que es ya uno de los "clásicos" de la nueva novela latinoamericana. Es sintomático, desde el punto de vista de la estrategia cultural cubana, que este otro volumen de la serie esté dedicado a un novelista que ha manifestado sin reservas su adhesión a la causa. (El hecho de que Pedro Páramo haya sido escrito con ayuda

\footnotetext{
${ }^{18}$ Véase, “Juan Carlos Onetti y El astillero," en Casa de las Américas, no. 26(La Habana, octubre-noviembre 1964), pp. 117-119.
} 
de una becaconcedida por la Fundación Rockefeller es un detalle sobre el que los cubanos parecen haber decidido no hacer mayor hincapié.)

El tercer volumen de la serie dedicado a un novelista latinoamericano es el de García Márquez (259 pp.; tirada de cinco mil ejemplares). La recopilación estuvo a cargo de Pedro Simón Martínezy fue publicado también en 1969. Recoge veintiocho trabajos largos, sólo uno de los cuales es cubano. Una vez más, la colaboración es de Reinaldo Arenas y cuenta entre las más importantes. Su ensayo, "En la ciudad de los espejismos", está lleno de brillantes observaciones y finísimas lecturas. Hay una colaboración cubana, en la sección, "Otras Opiniones", pero no parece demasiado interesante. ${ }^{19}$ Una tercera colaboración que técnicamente podría ser considerada cubana es la de Julieta Campos, pero como esta escritora vive en México desde 1955, no creo que se la pueda considerar aquí. En conjunto, el volumen refleja el interés internacional que ha despertado la obra de García Márquez en general y Cien años de soledad en particular. También revela el éxito que esta novela ha tenido en Cuba: una primera edición de diez mil ejemplares en 1968 fue seguida en 1969 por una segunda de ochenta mil.

El caso de Garcia Márquez requiere un examen algo más detallado. Es evidente que de todo el grupo estelar del Boom--lo que en algunos círculos se ha llamado la Mafia--, García Márquez es el único que ha logrado tener éxito simultáneamente en los países occidentales y capitalistas, y en los paises del mundo socialista. Su estrategia política ha sido extremadamente hábil. Uno de los primeros adherentes de la causa cubana, García Márquez trabajó como corresponsal en New York de la agencia cubana Prensa Latina hasta que la ruptura de las relaciones con Estados Unidos, después de que Fidel Castro declaró que la Revolución era marxista-leninista, lo dejaron cesante. ${ }^{20}$ Desde México primero y luego desde Barcelona; García Márquez ha seguido de cerca la causa cubana. En 1972 en ocasión de recibir el segundo premio Rómulo Gallegos, donó públicamente el importe del premio al grupo político venezolano que tiene lazos más firmes con Cuba. Aunque en ocasión del Caso Padilla su nombre apareció asociado a los de los firmantes de la primera carta, él aclaró inmediatamente su posición: no la había firmado ni se adhería a la crítica que ella implicaba. Es más: confiaba en que Fidel aclararía satisfactoriamente todo. ${ }^{21}$ Desde entonces, García Márquez ha proclamado reiteradamente su adhesión al socialismo y hasta (tal vez en serio) su decisión de abandonar la literatura para dedicarse a la política.

Con esta trayectoria es obvio que su figura resulte mucho más aceptable para los dirigentes de la politica cultural cubana que la de escritores más críticos como Carlos Fuentes, Mario Vargas Llosa y (hasta) Julio Cortázar. No quiero decir con esto que en la selección de autores para la serie de Valoración Múltiple sólo hayan predominado razones de indole estratégica. De ninguna manera. Los tres narradores escogidos son indudablemente escritores de primer orden.

19 Es de Francisco de Oraá y se transctibe en las páginas 229-231 de la mencionada Recopilación.

2u Según Luis Harss y Barbara Dohmann, en Los nuestros (Buenos Aires, Sudamericana, 1966, p. 388), "pronto sus relaciones con Prensa Latina se deterioraron, y cuando las cosas se iban al diablo, renunció."

21 Véase Libre, no. 1, pp. 135-136, para la posición de Garcia Márquez frente al Caso Padilla. 
VIII.

Llegamos, pues, a la conclusión de este largo aunque sintético periplo. Una de las primeras comprobaciones es que la critica de la nueva novela en Cuba es insuficiente, por lo menos hasta 1971, que es la fecha que nos hemos puesto como limite de este trabajo. El material crítico es escaso, no hay una perspectiva muy nítida desde el punto de vista analítico, los mejores trabajos pertenecen por lo general a escritores que no representan la posición oficial, como Reinaldo Arenas. Lo que sí hay es una estrategia cultural muy clara. Esa estrategia crea o destruye valores por métodos que no son estrictamente críticos. Grandes ediciones de obras de autores que el régimen considera seguros (noventa mil ejemplares para Cien años de soledad) al lado de reducidas ediciones de escritores que el régimen tolera pero no quiere fomentar demasiado (cuatro mil ejemplares para Paradiso); volúmenes de homenaje y revaloración para ciertas figuras de actuación favorable a la revolución (Onetti, Rulfo, García Márquez), junto a la discreta omisión de nombres conflictivos (Cortázar, Fuentes, Vargas Llosa); promoción publicitaria indisimulada para los funcionarios del régimen (Lisandro Otero, Edmundo Desnoes) opuesta al silencio y la censura de otros nombres mucho más importantes (Reinaldo Arenas es el mejor caso); finalmente, censura total o ataques políticos violentísimos a los escritores que el régimen considera como enemigos (Cabrera Infante, Severo Sarduy).

Es evidente que semejante estrategia política no puede fundar una crítica responsable. La calidad literaria de una obra de arte no depende de su ideología. Si así fuera el socialismo debería eliminar toda la literatura no revolucionaria, de Platón a Goethe, de Dante a Dostoyevski. Es obvio que debe haber otro criterio. En el campo marxista, el problema de una crítica literaria que no cometa los errores intelectuales del estalinismo y del "realismo socialista", ha ocupado a pensadores y críticos ilustres, desde los formalistas rusos hasta el grupo de criticos alemanes que representan Walter Benjamin y Adorno, para no citar sólo a la escuela Lukacs-Goldmann. Ese pensamiento marxista serio y responsable está empezando a hacer algún impacto en la crítica cubana. Seguramente que dentro de unos años, una valoración desde el punto de vista marxista de la nueva narrativa latinoamericana será posible en Cuba.

Pero el hecho de que, hasta 1971, por lo menos, no exista esa crítica ha determinado que la valoración de la nueva novela en Cuba haya tenido un efecto lamentable en América Latina. Veloces teorizadores de distintas nacionalidades (algunos de varias al mismo tiempo) se han dedicado a erigir listas de buenos y malos narradores. Apoyados en la estrategia cultural cubana, han dividido el campo en los ortodoxos (gente como Onetti, Rulfo, García Márquez) y los heterodoxos (Cortázar, Fuentes, Vargas Llosa). Han promovido polémicas y en algunos casos han arrastrado a estos mismos escritores a una discusión pública de lo que no se puede discutir en un nivel ideológico tan primitivo. En todas estas clasificaciones, elogios y diatribas, ha abundado la política y ha escaseado la crítica. Es hora de abandonar estas irresponsables actividades. Es justificable que en Cuba, país pequeño que nunca ha tenidomuchos críticos literarios aunque tiene,'desdel Heredia y Martí, algunos excelentes, la crítica no esté todavía completamente desarrollada; lo que no es justificable es que en el continente entero la valoración de la nueva novela se haga de acuerdo a patrones estratégicos que ni siquiera funcionan siempre en Cuba. Es hora de que 
se pueda separar la adhesión política y emocional que despierta la causa cubana, por su firme posición anti-imperialista, por su confianza en un mundo mejor, de la adhesión a métodos críticos y estrategias culturales que pueden justificarse en el confinado recinto de una cultura sitiada pero no tienen ninguna justificación en el campo abierto de la crítica internacional. Si la nueva novela latinoamericana merece ser considerada por la crítica, esa crítica debe ser abierta y debe ser, sobre todo, literaria.

Yale University

EMIR RODRIGUEZ MONEGAL 